\title{
Housing Dilemma and Vertical Dimensions
}

\author{
Muhiuddin Bahauddin Yusuf ${ }^{1}$, Islam H. Elghonaimoy ${ }^{2, *}$ \\ ${ }^{1}$ Researcher in Housing and Urban Design, University of Bahrain, Kingdom of Bahrain \\ ${ }^{2}$ College of Engineering, University of Bahrain, Kingdom of Bahrain
}

Received July 22, 2020; Revised August 12, 2020; Accepted September 23, 2020

\section{Cite This Paper in the following Citation Styles}

(a): [1] Muhiuddin Bahauddin Yusuf, Islam H. Elghonaimoy, "Housing Dilemma and Vertical Dimensions," Civil Engineering and Architecture, Vol. 8, No. 5, pp. 1107 - 1118, 2020. DOI: 10.13189/cea.2020.080537.

(b): Muhiuddin Bahauddin Yusuf, Islam H. Elghonaimoy (2020). Housing Dilemma and Vertical Dimensions. Civil Engineering and Architecture, 8(5), 1107 - 1118. DOI: 10.13189/cea.2020.080537.

Copyright $\odot 2020$ by authors, all rights reserved. Authors agree that this article remains permanently open access under the terms of the Creative Commons Attribution License 4.0 International License

\begin{abstract}
Bahrain is a small island suffering from land scarcity, caused by the limited land area and the overpopulation. Bahrain will face dramatic problems in all life levels due to the frequent use of horizontal urban growth. However, by observing coastal countries such as Bahrain, Singapore, Japan, etc., some governments tend to reclaim land upon the surrounding water body, to provide enough area for urban development. This results in harming the nature and disturbing the ecology of the environment. Therefore, these issues have made designers think about a solution of accommodating a large number of inhabitants with less land area; intended for a sustainable urban solution to cities and limiting the land reclamation upon the seawater cases. Moreover, the idea of this research is to focus upon building communities vertically, giving a solution for the sustainable vision issues: the natural environment, the social and the engineering elements publication.
\end{abstract}

Keywords Vertical Cities, Sustainable, City Problems, Urban Heat Island (UHI)

\section{Introduction}

The Kingdom of Bahrain is expected to reach a population of 1.592 million in the year 2020. In the year 2030, Bahrain will reach to 2.128 million (figure 1). However, the population was 621 thousand in the year of 1999. The average rate of growth is $7.4 \%$ (Ministry of Information Affairs-Kingdom of Bahrain, 2020). The demand for housing units in terms of low and medium-income families is increasing. Every year a range of 3,000 marriages occurs, assuming that $50 \%$ are in need for housing units; this gives a total of 1,500 houses per year (Kingdom of Bahrain - eGovernment Portal, 2019). The high density in urban areas in Bahrain is caused due to the rapid concentration of people living in a particular metropolitan area such as Manama, Riffa and Muharraq. However, with high density, destinations become more walkable and provide the opportunity of different transportations. Consequently, the aim is to find a solution, which avoids urban sprawl and combines all the needs of an individual in their life in a sustainable way to the current urbanization pattern and trends in Bahrain. Nevertheless, the fact that based on the population increases, living spaces will need to be created. However, building houses and neighbourhoods most likely results in the destruction of natural habitats. Therefore, the research hypothesis is that the Vertical Cities are the sustainable key for solving the housing demand problems in Bahrain. Hence, the research is based upon two main objectives, the theoretical and the literature reviews, as well as technical issues. The theoretical and the literature reviews discuss the urban land issues and housing demands, as well as finding a suitable approach towards urban growth. Furthermore, explore the informational depth of Vertical dimensions in solving housing problem in Cities. The technical issues will help implement the idea to real life in Bahrain. The research problems are summarized as follows.

\section{Major Reasons of Housing Problems}

In Bahrain, Urban growth is caused by the increase of the population and due to the physical expansion of towns. 
Consequently, Urban sprawl is related to urban growth (El-Dardiry \& El-Ghonaimy, 2016). When sprawls are built, lacking smart growth planning, it causes an unsustainable environment, which forces the community to rely on automobiles for transportation and different quality of lives, resulting in an untenable situation. Smart growth is planning areas, which are near the city; one will be able to use bikes and public transportations (El-Dardiry \& El-Ghonaimy, 2016).

Unfortunately, the government started to reclaim land due to the land scarcity, caused by the overpopulation. This is costing the government high expenses. Consequently, land reclamation harmed the environment and marine life Bahrain has announced seasons for fishing, as the marine life has become miserable due to the reclamation of land. The factories around the city and the lack of greenery caused air pollution (El-Ghonaimy \& Javed, 2018). On the other hand, the country began to design villages with residential buildings instead of private houses; nevertheless, it still did not solve the problem as the population is increasing rapidly.
Moreover, urban areas became congestion and a high density is caused due to people living in a particular urban area. However, some urban planners vision this positively, as with high density, destinations become more walkable, and the opportunity of different transportations will exist. High density leads to higher traffic crowd (El-Ghonaimy \& Mohammed, 2019).

Consequently, there is a declining Infrastructure within the urban areas, which needs comprehensive improving plans. Improved infrastructure means the improvement of public resources, such as roads and electricity, reaching everywhere around a country. However, the development in a sense and the quality of life led to the rising of standards of living. People started to be able to pay to travel more and reach distances to work. In addition, they love to live in a calm environment without the crowd and with less traffic. Therefore, man started to sprawl out, causing harm to the environment. They started to cut trees, leading to the disappearance of green areas and the constructing of poor infrastructure of roads (Nechyba \& Walsh, 2004).

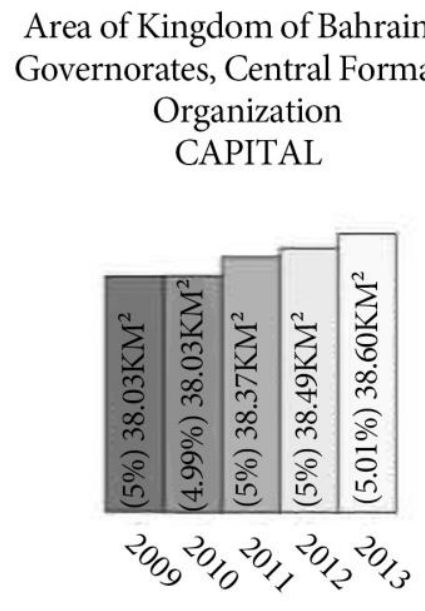

Area of Kingdom of Bahrain by Governorates, Central Formatics Organization

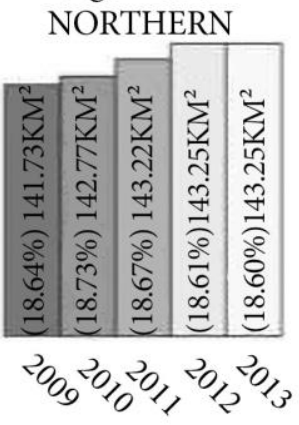

Area of Kingdom of Bahrain by Governorates, Central Formatics Organization

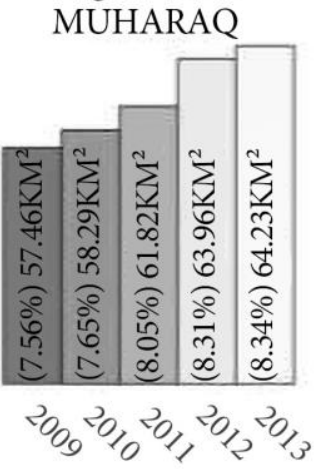

Area of Kingdom of Bahrain by Governorates, Central Formatics

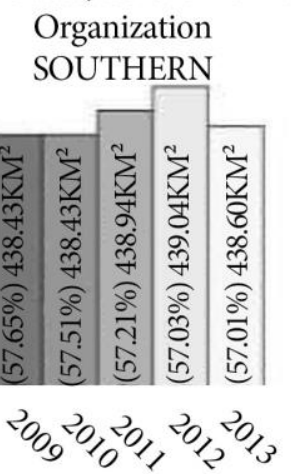

Area of Kingdom of Bahrain by Governorates, Central Formatics Organization CENTRAL

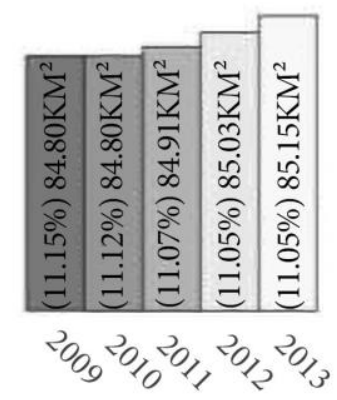

Area of Kingdom of Bahrain by Governorates, Central Formatics Organization TOTAL AREA 100\%

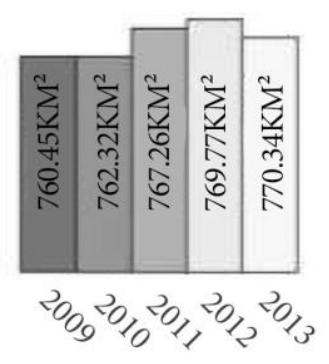

(cio.gov.bh, 2017, developed by Author, 2018)

Figure 1. The Rate of Area of Kingdom of Bahrain by Governorates from 2009-2013 
Moreover, historically, the housing problems in Bahrain has many influences. The transformation from a Village Society to a Developed Urban Society became serious phenomena. Bahrain opened a widespread market for developments. This led to the transformation of the country from a village society to a developed urban society. However, the population has grown from 661,317 to more than 1 million in 2008. This development and movement had a negative impact. As the investors are designing plans for their own purposes, led to the creation of suburbs. Suburbs are a problem in urban designing, which is creating separate districts away from the central city. Moreover, the government started giving land with houses unconsciously to civilians, shaping the Bahraini intellect to refuse the concept of an apartment. This caused problems, as the population is increasing, they have to start reclaiming lands and building housing projects and districts. "Figure 1" is explaining numerically how the problem is overgrowing (Wiedmann, 2010).

One of the important factors that affects the housing problems is the population Increase. Bahrain opened a broad market for developments. This led to the population's growth from 661,317 to more than 1 million in 2008. This development and movement had a negative impact (figure 2). Consequently, the Ministry of Housing, Kingdom of Bahrain provides ranged income families with affordable housing units, with an ease of payment. There is a percentage of houses for the families, who have limited income that does not own housing units. The ministry is working towards providing every family with a unit. Bahrain invested 208 million dinars into housing programs. This investment aims to provide affordable housing units and reducing the government's housing waiting list. The vision is to provide limited income families with suitable and appropriate dwellings.

Conclusion of this part, there are significant forms of problems are resulted. Social problems in tem of the loss of the traditional quality and the absence of the community due to the changing the residences lifestyle and the segregation between classes. An unhealthy neighborhood for social interaction and social pollution besides the scattering of life facilities and services. Moreover, different forms of pollutions such as water pollution and air pollution. Serious economic problems are resulted for the land prices especially for housing issues and energy consumption and declining in Applying Bahrain's vision of 2030 .

\section{Vertical City, Sustainability and Solving the Housing Problem}

Bahrain's main goal and vision of 2030 is to build for human needs. If we accept the most significant percentage of the country's construction is dedicated to housing, as well as, the current trends for sustainable urban development focuses on the designing of vertical communities, it is essential to explore the concepts of sustainable development and architecture. Also, the idea of community/neighbourhood,

village/city, horizontal/vertical development, etc. In other words, we need to have populated settlements in vertical buildings. It is a group of permanent residence, located close to each other, enabling its people to be social and get closer to each other. A Vertical City has its specific laws towards lands, housing units, sanitation, utilities and transportations. Furthermore, to make transportation easy on foot and attract people to visit built places. Transportation systems are more straightforward compared to a city, as it is smaller in terms of land area and population. The structure has a religious centre and shops, which one can buy their basic needs (Pateman, 2011).

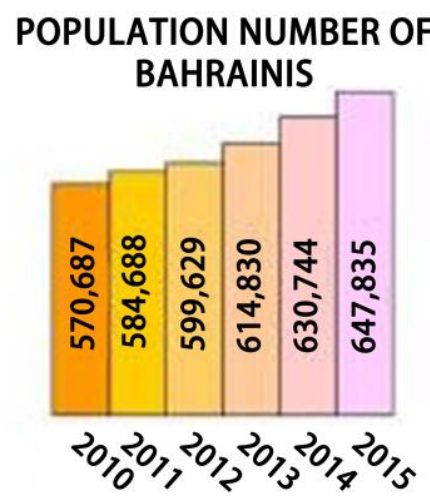

\section{POPULATION NUMBER OF NON- BAHRAINIS}

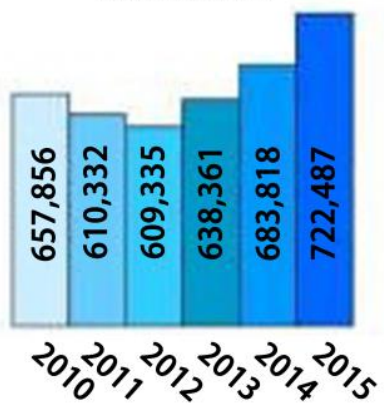

\section{TOTAL NUMBER OF POPULATION}

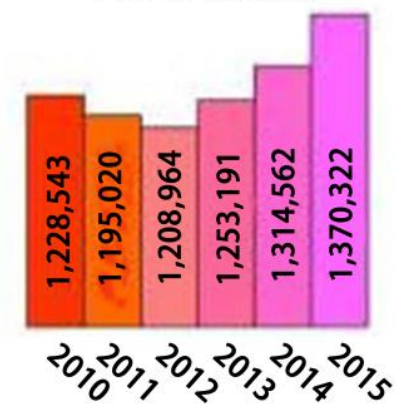

Figure 2. Bahrain's Rate Increase of the Population from 2010-2015 (Data.gov.bh, 2017, developed by Author, 2018). 
While talking about the sustainable architecture and a Vertical City (high-rise buildings), we have to rise the vision of creating a forming of a Community (group) of people living and working together in the same area. Sustainable architecture focuses primarily on the proper use of energy and the managing of conservation it. Moreover, it is innovative in the way of people's living. Green architecture is part of sustainable development. This role of designing a green building will involve architecture, construction, structure, green building materials, maintenance, etc. Human development throughout the years has led them to the development of technology and medicine; this enables man to live longer and healthier lives. However, this brings a problem of the overpopulation (Al Najjar, 2018). However, those people practice different activities in their daily lives. For example, working, learning, shopping, etc. will be provided, connecting the people in the same structure (Al Najjar, 2018).

Moreover, A Vertical City has continuity, differentiation and endless circulation, giving the sense of a city, but a skyscraper or a tower is repetitive floors with vertical circulation. The vertical spaces will respect sustainability in terms of social, environmental, economic, accessibility, aesthetic, functional and sustainable issues.

a Social Character that Solving social problems via controlling the segregation, through a healthier mix of different ethnic groups and enhancing the people's lifestyles by reducing the amount of time spent in traffic, as a result of giving them all their needs in proximity. Beside the creating healthy neighborhoods for social interaction, enhancing and forming communities and providing most of the sorts of life facilities and services in one place

In addition, the aesthetic character by creating a landmark, showing people what cities could be. Moreover, have a building, which is in top of the art in terms of material and technology, as well as a response to the climatic and the environmental factors. It will help in enhancing visual quality with providing vertical agricultural gardens.

While the economic character will help in solving the housing issues and a new way introduced to the region and giving character and meaning. It will create different spaces with different identities and providing vertical agricultural gardens, which will create job opportunities and encouraging production families within every vertical cluster, moreover, reducing the cost of transpiration, shipping and time. Moreover, the Use of eco-friendly methods in constructing and designing. Controlling the significant reasons for land reclamation

In the future, the only possible way to accommodate the rapid increase in population is by vertical living. To design a Vertical City, architects will think to combine mixed-use facilities and complexes within one building, some spaces are public, and some are private. High tech, site and sustainability in the design is used concerning the culture. Also, thinking about the people's need and daily life activities, according to the cultural requirements. It will have residential, commercial, educational, outdoor and public spaces. It should offer a 24-hour living center.

It should be noted that, In the plan of the year 2030, new cities and towns will be built within different areas. Therefore, the proposing of vertical cities can be part of the urban context. The vertical cities will be built, offering more residential spaces within its urban fabric. It will enhance and overcome the obstacles of the ministry of housing and works in providing the solution to the overpopulation of the citizens. It will influence positively upon the environment that Bahrain has released actions regarding environmental issues, to try to control the air pollution, climate change, water conservation, marine life and land resources. While socially, building factors, which will lead to prosperity in the community. Economically, having green solutions towards building a better economy. In addition, reducing energy consumption, clean energy technology, eliminating pollution water resource management and conservation of biodiversity.

Searching for the International Experiences in Applying Vertical Cities to have lessons, the case studies in hand are about vertical cities, which are under construction, vision or built. One of these case studies is the "Endless Vertical City", which has richness in its components and design. The case's components will be used in terms of the manipulation of spaces, to have the village opened to the street without obstructions, as if it is part of the horizontal urban context. Also, the exposing of services and facilities to each other. For example, the ones, which are located towards the urban streets, following the urban scheme. Moreover, there will be a sense of continuation and easiness, and public gardens will be located on every several floors within the complex. The project follows the urban ordering, but vertically. Each part will be designed individually as to represent the function based on levels so that users will have a sense of direction (Figure 3).

The other case is the Shenzhen Logistic City, which helped in understanding a vertical city, as there should be a fast vertical circulation movement between spaces. The social and spatial interactions are the highest priority, providing sunlight according to the need of the spaces; by the manipulation of spaces and the shape of the building. Creating spaces where people will interact with each other, while achieving their purpose of buying, working and living within the structure. Also, using the urban pattern and scheme (figure 4).

The last case is "De Rotterdam" which is following the urban scheme, which can be used in the project. However, going from private to semi-private to the public gradually and giving intention to the community and the social life of the occupants. Moreover, the building should be near a public transportation facility and have easy accessibility with endless design. Parking is on the ground floor 
basement then comes to the offices (figure 5)

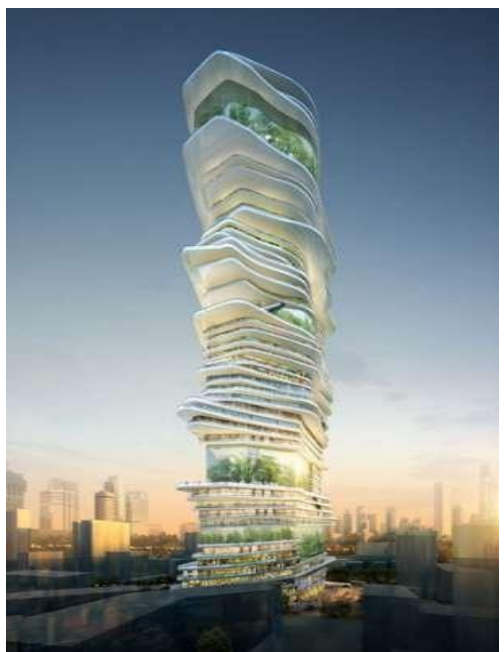

Components:

a. Parking

b. Commercia

c. Offices

d. Housing units

e. Gardens, public spaces \& facilities

f. Educational

g. Vertical circulation: ramps (Sure-architecture.com, 2015).

Figure 3. Endless Vertical City; Shoreditch, London, UK (Sure Architecture, 2015)

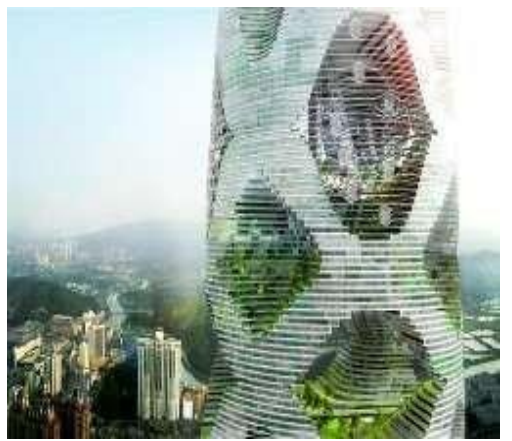

Components:

a. Parking

b. Commercial

c. Offices

d. Housing units

e. Gardens, public spaces \& facilities

f. Reception Information

g. Vertical circulation: tram (Yoneda, 2010)

Figure 4. Shenzhen Logistic City, Shenzhen, China (JDS Architects, 2006)
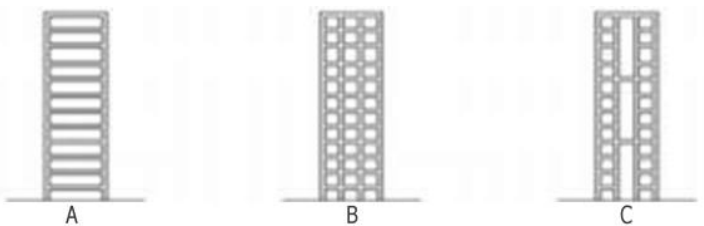
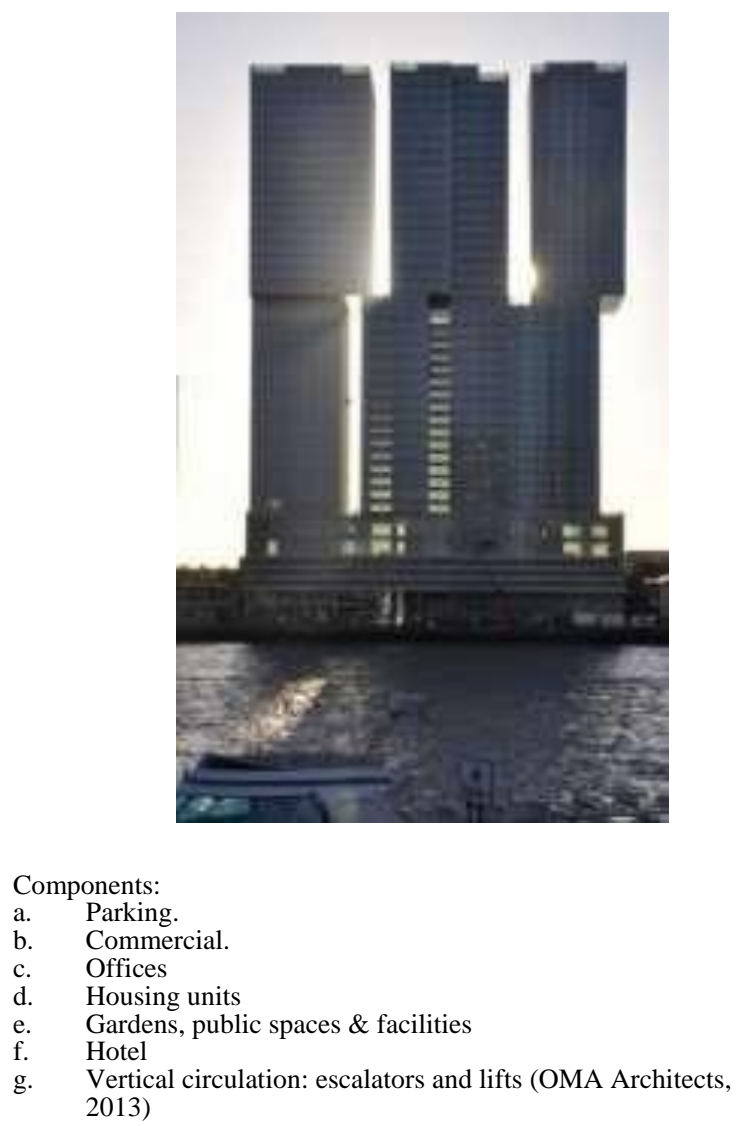

Figure 5. De Rotterdam located in Rotterdam, The Netherlands (OMA Architects, 2013)

\section{Moving to the Technical Issues, some items should be considered such as:}

The Structural; that the City will have a hybrid structure. It is used when creating an un-regular shape of a building. The hybrid structure will be used to achieve the building's construction, as explained in figures 6 and 7. Different structural systems are presented in figure 6: model A represents a framed tube system, while $B$ represents the bundled tube system, however, $C$ represents the tube in tube system, D represents the diagonalised system, moreover E represents the core and outrigger system and $\mathrm{F}$ represents the hybrid system (figure 7).
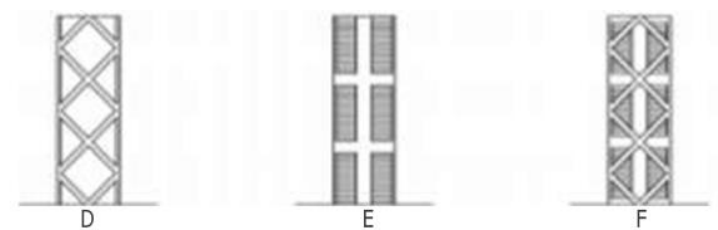

Figure 6. Types of Structures (Hallebrand \& Jakobsson, 2016) 

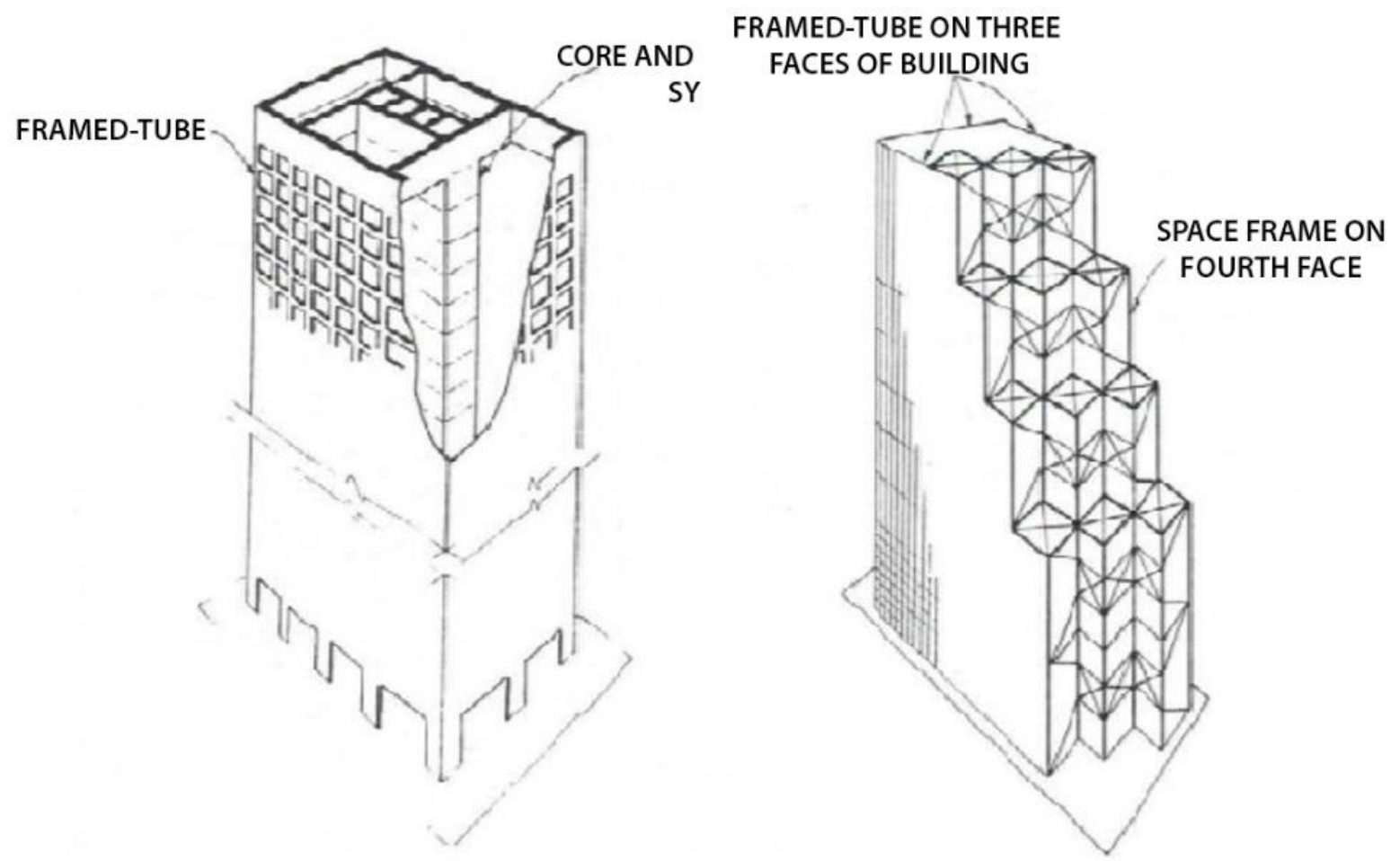

Figure 7. Hybrid Structure (Rana \& Rana, 2014)

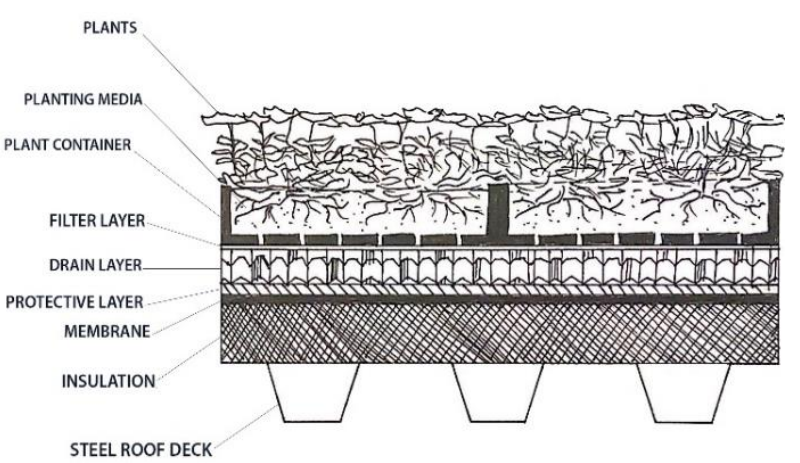

(Wark \& Wark, 2003, developed and drawn by Authors, 2020)

Figure 8. Extensive System

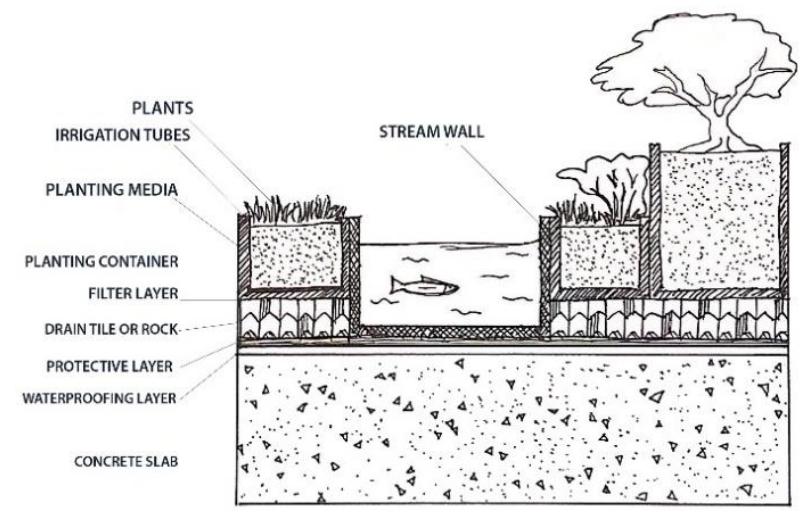

(Wark \& Wark, 2003, developed and drawn by Authors, 2020)

Figure 9. Intensive System
Greenery Issues; Green spaces are a major element in designing the urban context. Green roofs are provided within the vertical city, either extensive or intensive. The motivation behind giving green territory is to mollify nature at high-density residential structures, particularly in urban regions. The ecological wellbeing will progressively get disturbed without green spaces as shown in figure 8 and 9 (Shukri \& Misni, 2017).

Special Building Services; (Specialised systems) that suit high-rise buildings are the mechanical and electrical services. Those services are vertical circulations, plumbing, HVAC, firefighting, gas supply and garbage systems. They should be in smart high technology systems (Shukri \& Misni, 2017). The Smart Garbage Treatment System should have a room for temporary garbage storage on each floor of the structure, as it is essential. The caretaker will take the garbage and the recyclables from the warehouse. Another more practical way is to install a garbage chute, which leads to the central garbage room at the bottom or ground floors of the building. There will be different chutes, one for the garbage and the other for the recyclable wastes. Overbearing the tremendous height of the structure, there will be transit levels every particular floor. The caretakers will upload the garbage to the service lifts to the ground floor to the garbage truck. The caretaker will empty the trash and the recyclable garbage storages located at the lower levels of the structure (Department of Environment and Climate Change NSW, 2008). Providing a chute for The Vertical City is more economical and easier (figure 10). 


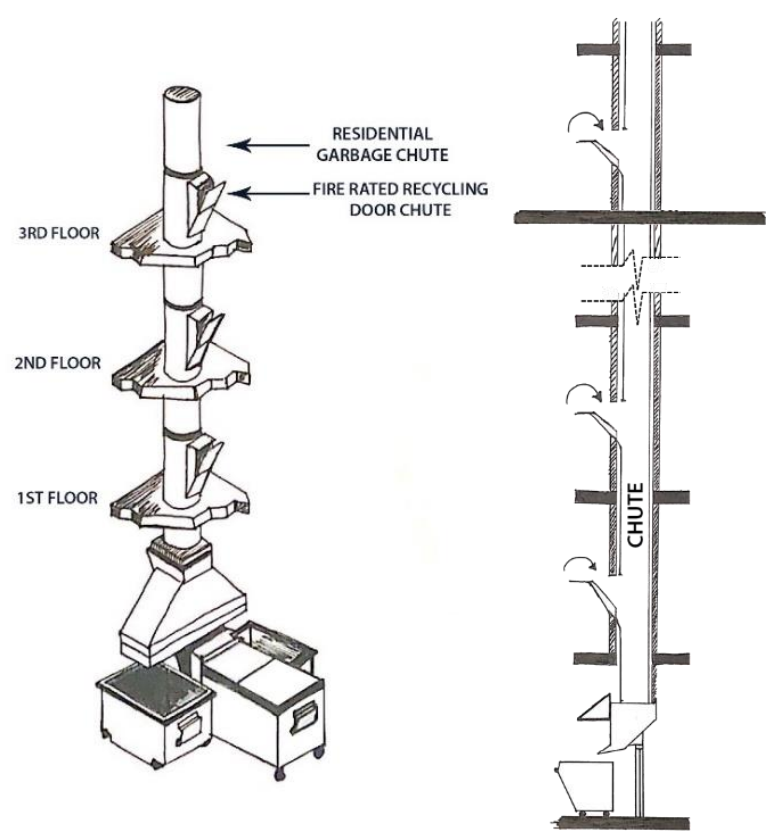

Figure 10. Garbage Chute Mechanism (Ecotech Chutes Pvt. Ltd., 2020, developed and drawn by Authors, 2020)

While for the HAVC, a green and smart HVAC system refer to heating, ventilating and air conditioning. It should be considered to avoid the expecting overload of the traditional methods, which saves energy. The HVAC system interacts with the lighting system in the envelope system. High-performance HVAC results in significant energy savings. It will save 30 percent reduction in the annual energy cost with a payback period of three to five years. Heating and cooling will be designed using the ASHRAE standards (City of New York Department of Design and Construction, 1999).

Moreover, for a smart vertical circulation, geared and gearless traction elevators are used in high-rise buildings, capable of high speed. Gearless motors will save up to 25 percent of energy when compared to geared motors. Another advantage of gearless engines is that it runs faster, as they have a higher torque. So gearless traction will be used in the Vertical City, preferred to be in the centre. The gearless traction elevators will be specially designed, respecting different factors to reach to the highest point. Those factors are the time of arrival of the lift, safety precautions, pressure, durability, etc. (Al-Kodmany, 2015).

Fire Precaution should be considered while designing, that foe the lower floors will have fire-rated exit staircases, with a separated structure. The fire staircase walls will have a separate structure. Nevertheless, when going to the upper floors, the structure will be equipped with different systems for emergencies; system visual monitors and emergency communication. Those systems help in guiding the people through announcements and instructions to the Occupants and non-occupants. There are elevators designed for firefighters for rescuing. The building will use programmed enhanced lifts for emergency events and evacuations, as well as, helicopter landing area. Occupants and non-occupants on the highest floors will reach transfer floors. They will enter to the express elevators to reach to the ground floor (Kinateder, Kuligowski \& Omori, 2014). However, the Fire Precaution still significant challenges while thinking about vertical cities.

In skyscrapers, plumbing as shown in figure 11 the tanks should be multi-staged to supply the sweat water to the upper floors without damages, such as damaging the pump. The water pressure transmits the water from the main tank, then to the other tanks by gravity, until the water reaches all the floors (Gupta \& Thawari, 2016).

In addition to the use of the solar in heating the water for different uses should be considered, which is connected to solar panels, transferring the heat to the tank (United States Environmental Protection Agency, 2020).

Moreover, for the drainage systems and the treating of the black water should be disposed as well, while the grey water will be reused to irrigate the greenery within the Vertical buildings. The recycling of Grey Water needs separate network that after the sweat water supplied and distributed to the whole building, the wastewater will flow down by the high gravity load via special network pipe (figure 12) using a different technique. The greywater (no longer wastewater) will move from the upper levels, pouring fast as a bullet, so it requires slowing dawn via service floors in multi-stage

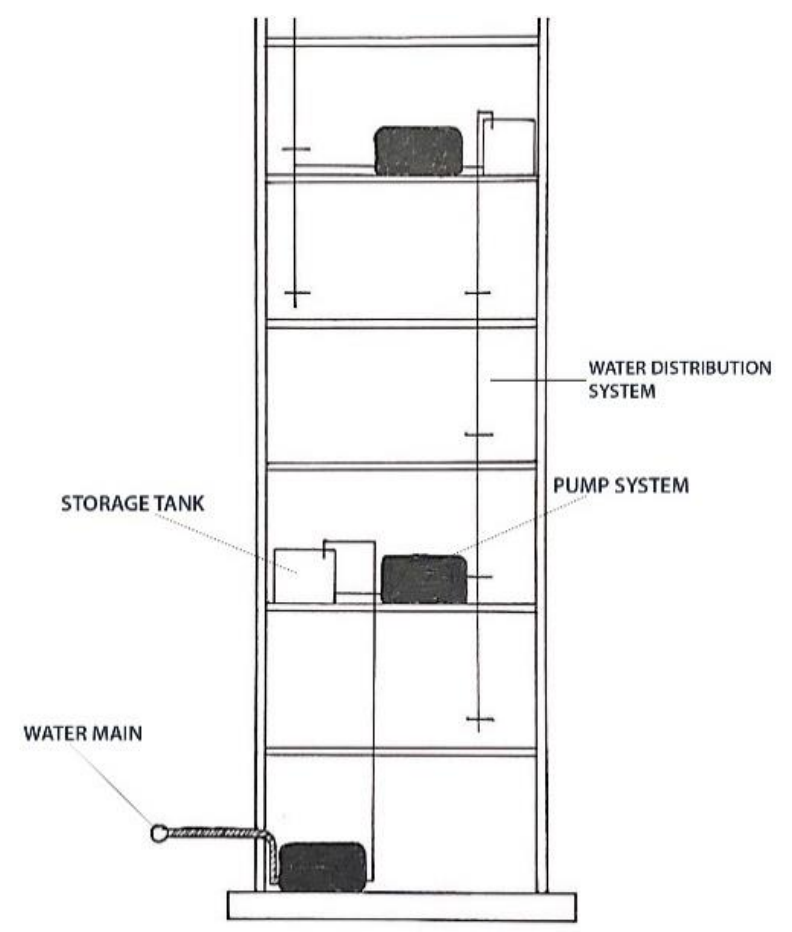

Figure 11. Multiple Pump System (Dummies, 2017, developed and drawn by Authors, 2020) 


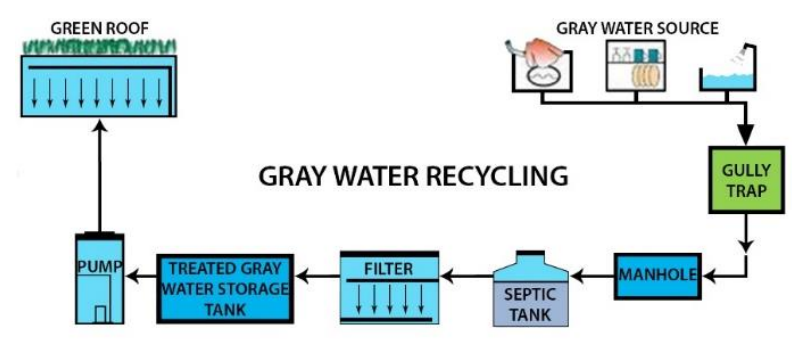

Figure 12. Grey Water Recycling (Authors, 2018)

\section{Results}

According to Gulf Insider [28], has reported that in 2017 Bahrain had a shortage of housing units of 75,000. Also, during 2017, established according to the population statics and the standard accommodation of dwellings size are for 290,000 units and the available are 216,000 units. Nevertheless, when we consider the housing quality.

Architects and town planners cooperate to reach the suitable conditions for houses to accommodate the living of humans. Cultural characteristics and socioeconomic of the community are serious roles and issues. Those roles and issues are respected with their conditions when designing housing units. Moreover, vertical cities represent sustainability and affordability, fulfilling and acting towards the housing conditions, with an appropriate price, architects and planners find this a big challenge. Categorising the housing conditions into a variety of groups, yet the categorisation that can be considered to be appropriate containing three groups.

The environmental conditions, including noise and climate, belong to the first group. The noise and climate discusses humidity, heat and ventilation. Design aspects and housing materials, including construction, materials, building, finishing materials, density and privacy belongs to the second group. Moreover, the proper provision of services belongs to the third group. The proper provision checks and verifies satisfactory and suitable standards for the living, consisting of electricity, potable water, and appropriate sewage disposal system and garbage collection.

Moreover, building communities vertically, giving a solution for sustainable vision issues: the natural environment, the social and the engineering elements. Therefore, when considering the quality of the sustainable vertical housing projects, it should consider the following conditions

a. Environmental housing conditions in term of noise, thermal and Heat factors, as well as, humidity and condensation, ventilation in houses and in the spaces between, allowing the wind flow between spaces, and letting natural lighting and ventilation to all living provision of the spaces between the units to go through the vertical cites. Having greenery upon roofs and facades will act significant progress towards controlling the reasons of Urban Heat Island (UHI).

b. Economically, consider modern technology for the provision of services for each unit in term of electricity, water supplies, Sewage disposal, and Solid waste management. Going vertically will reduce the load upon transportation and traffic, roads, and movability in City, which are significant problems in the city. Of course, it will need special treatment of vertical infrastructure and wastes treatment. Recycle and reuse the greywater will be a priority in dealing with this Vertical Dimensions issues. Structure system and emergency evacuation is still a point of discussion. Number of car parking in the city will be reduced, which will reduce the daily cost of travelling for the residences outside their vertical city.

c. Socially, housing design and the relation between Vertical cities' components, construction system, Privacy \& Density, Aspects of design, and Building materials. Moreover, the Communal spaces should set aside for recreational activities for the different age group. These Communal spaces in between and distribution of the uses and functions to create healthy and comfortable spaces between the Vertical cities components as well as having suitable social Interaction spaces. Moreover, access to houses can be achieved without the sacrifice of privacy to other adjoining. The properties of communal spaces should have a proper laying out of housing units, allowing for the reasonable distance between the units. This will allow the permitting of the preservation of privacy, provision of satisfactory through access, through maximum use of footpaths and managing to a great extent the possibility of privacy. Children will have spaces in safe of traffic problems this, consequently, would protect their lives, but it may create noise from the other hand. On the other hand, the designer should consider the phobia of the high rise building upon category of residences.

Therefore, Vertical Cities are a sustainable solution for accommodating a large number of inhabitants with less land area; for limiting the land reclamation upon the seawater cases, providing the needs of every citizen, reducing the expenses in reclaiming land and controlling the land scarcity.

From field survey and the analysing of different case studies, they mostly contain housing units, offices, commercial, service facilities and public parks. They are located near public transportation, as well as they have an impressive vertical circulation, which is fast. All of them are creating a community and a neighborhood, mostly by providing public gardens and spaces throughout the structures. All following the horizontal urban pattern with the open spaces. Moreover, parking is on the ground floor, or basement then comes to the offices or the facilities. Housing is located within the upper levels. In those 
complexes, every specific storey has a garden or a public space or mixed facilities within the general context or an open court, from where an individual will start their adventure through the building. All of the cases are manipulating the spaces and the building, to provide the maximum natural lighting and ventilation. Having vertical cities requires the understanding of different aspects and issues towards the followings.

While talking about the selection Criteria for Site, The Vertical Cities criteria for selecting the location of the site illustrated in table 1 , as well as programs and technical guidelines.

Environmental Criteria; corresponds to basic needs of air, noise and light quality, as well as, views. This factor should not be the most important one, as a vertical city by nature, defies all these features through its height. Air quality - away from hazards sources of smell or air quality. Beside the optimum exposure to sun and wind breeze, but also the assurance that the new building will not affect the wind and natural light quality in the area negatively. In addition, the quality of views from not only the building but also its effect on the surrounding area.

Urban Criteria; a vertical city is an independent entity, generally disconnected from its surroundings. However, there is a need to consider a healthy relationship between land and vertical development. From this perspective, in an ideal future, each vertical city would include the primary residential, working, service and commercial needs of citizens, while the surrounding area. In between, vertical cities would support the commercial, educational, health and primary functions of the country, such as hospitals and clinics, universities, schools and nurseries, research labs, etc. In addition, it should have ministries, banks, headquarters, shopping malls, public parks, etc. the accessibility that the building has to be located in a highly accessible place for private vehicles, public transportation and potential pedestrian routes; allocating public transportation hub (concentration of Bus, Metro, Train, Airport Buses, etc.)

A primary services support the proximity to main public support facilities such as government, services, educational, commercial (ministries, shopping malls, universities, headquarters and public parks). Besides, a dense and consolidated urban area with a compact and consolidated metropolitan area.

Social Criteria; refers to the suppression of an emergent need such as housing, services, education and so on, basic commercial and facilities need, offices/services and housing need

Economic Criteria; that concern the land availability and Cost. The cost of land should be balanced with the overall construction price, which means that considering the verticality, the price of the property does not need to be very low, as there is maximum optimization. However, it cannot also be too expensive to make the project accessible to Bahrainis and low-income citizens. Moreover, the added Value of the location within an area that as a shortage of basic services and commerce will mean an immediate revenue for the project. In addition to the visibility; considering the building is supposed to change the way Bahrainis live; it should be able to act as a landmark and highly visible from surrounding areas.

Therefore, it is recommended to locate the site within a mixed-use area, as there are medical, commercial, residential, governmental and educational facilities.

Moreover, the assumption for inhabitants' numbers within the vertical city program is very significant and should be studied carefully. An assumption of having a complex of 2500 inhabitants, one floor will contain six apartments, each for five inhabitants. Nine hundred employees are hired from the outside and an average of visitors per month of 2000 people. 1965 inhabitants who are occupying the building will visit the public facilities and services. However, there will be an estimation of 1500 visitors and employees within the services and facilities. So, 1965 inhabitants +1500 visitors $=3465$ people. Also, 93 apartments occupied by 590 Low-income workers. Thirty-one bachelor flats and serviced apartments for visitors and temporary workers, as well as, small boutique hotel with a total of 32 flats. The total number of flats and apartments 463. The total number of temporary and permanent inhabitants 2851 inhabitants. There will be two towers, each tower is 17 floors residential, and each floor has nine apartments: 17 floors $\mathrm{X}$ nine apartments per floor $=153$ apartments $\mathrm{X}$ two towers $=306$ housing unit.

Table 1. Site Selection Criteria (Author, 2018)

\begin{tabular}{|c|c|c|c|}
\hline ENVIRONMENTAL CRITERIA & URBAN CITERIA & SOCIAL CRITERIA & ECONOMIC CRITERIA \\
\hline Air Quality & Accessibility & Housing Need & Land Availability and Cost \\
\hline Optimum Exposure & Public Transportation Hub & Offices/ Services Needed & Added Value \\
\hline Quality of Views & Primary Service Support & Basic Commercial and Facilities Needed & Visibility \\
\hline- & Density & - & $30 \%$ \\
\hline $15 \%$ & $35 \%$ & $25 \%$ & - \\
\hline
\end{tabular}




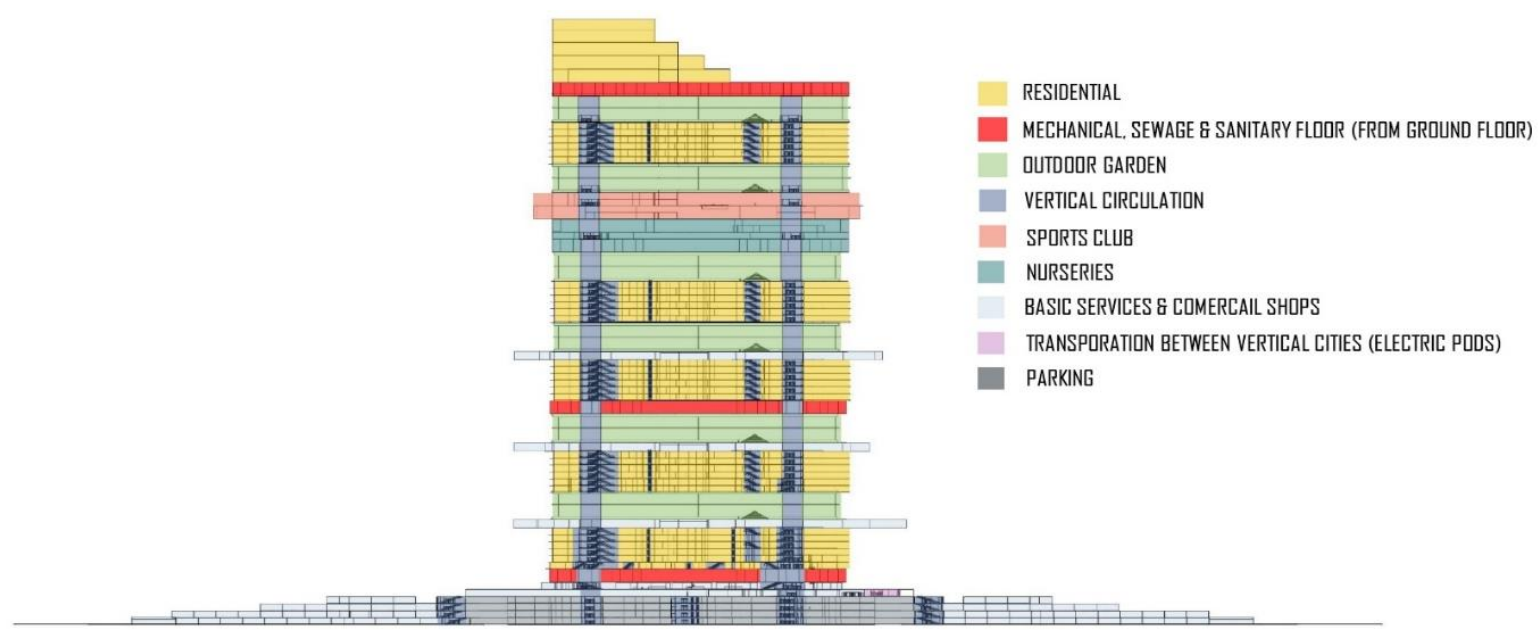

Figure 13. Vertical Distribution Section (Authors, 2018)

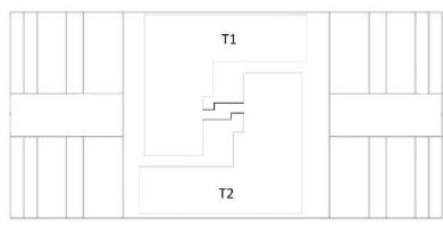

Building Top View

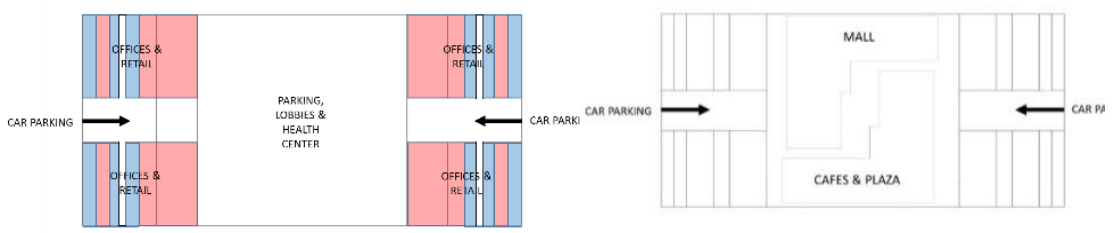

From Ground Till the Sixth Floor
First Plaza (Every number of floors)

Figure 14. Horizontal Distribution (Authors, 2018)

Therefore, the accommodation of 2851 inhabitants (about 570 families) within the project that runs by the governmental sector is 306 units $\mathrm{x} 400 \mathrm{~m}^{2}$ (area of the unit) $=122,400 \mathrm{~m}^{2}$ in the horizontal direction. This example shows the huge saving for the land in each project (figure $13 \& 14)$

\section{Discussion}

Warning the society that, "Land reclamation work had increased by 90 percent from 2002 to 2007" (El-Ghonaimy \& Javed, 2018), therefore the solving of the Housing Dilemma will be via the" Vertical Dimensions". It will help in solving the limitation of land as the sky has an infinite area. They will solve the housing problems, as will provide the need for individuals in a vertical sustainable environment. Those structures will stop the reclamation of land; congestion will be avoided in traffic and spaces. The Kingdom of Bahrain will have a better budget, as they saved and solved the treating of land, the housing issues and the architectural issues, resulting in an urban organization. The Bahrain strategic master plan 2030 considered this issue as a priority. The Vertical Cites are one of the key solutions to all of the above issues, saving the land and the marine. It will enhance the social aspects and offer a sustainable lifestyle, which is disappearing due to the negative planning of suburbs. The kingdom of
Bahrain is concerned regarding these issues.

Vertical City is a multifunctional building. A vertical village and a vertical city are planned and designed to offer all the necessary needs, facilities and services that a typical village or city possess. Achieving sustainable vertical cities and growing vertically is not an easy issue that when designing such projects. Vertical city affects and is affected by the guidelines of the Bahrain 2030 strategy for services, infrastructure, economic, social and environmental dimensions. The designers of such projects should integrate the principals of sustainability (social, economic and environmental) in their designs with the surrounding environment. The social characteristics of the users in general and the human comfort in particular, play a significant factor in succeeding such an idea. This social dimension could be achieved through an appropriate combining for the vertical city' components in term of the units designs and building construction system, suitable building materials, finishing materials, designing the outdoor spaces and the landscape around the house with respect to the environmental housing conditions.

Vertical City contains residential, public, entertainment, educational spaces, as well as food production, social and governmental services. On the other hand, multifunctional buildings include residential hotels, shopping centres and office spaces. Vertical is a solution to sustainable living; it has the potential to create a sustainable life (King \& Wong, 2015). 
Concisely, vertical cities community will create a new definition of a neighbourhood in the urban community of Bahrain. However, it will be functional, open to the public, approachable and endurable. Vertical cities are a sustainable solution to enhance the developing of urbanism in Bahrain. Furthermore, land scarcity will be overcome, and the ecology will be saved by controlling the reclamation reasons upon the surrounding body water. Vertical communities will be able to accommodate a large number of inhabitants with less amount of land. Also, controlling many sources of pollution resulting from transportation. Technology will be used to operate and creating smart solutions in the building to control and manage energy consumption.

The construction of such projects will develop the construction technology and techniques in addition to enhancing the skilled labour market and provide job opportunities for the residence in terms of engineering elements and the interaction of the social and the economic activities and facilities. The creating of new activities, events, and special types of trading will there as well. Land use, mixed-use, pedestrians and friendly community designs will be enhanced. Designers will be focused on the human scale, providing spaces for pedestrians, shops, work, reducing the traffic and benefiting residents' health. People will have a new alternative lifestyle, offering a variety of open spaces for housing units, shopping spaces, transportations. This will lead to the controlling of the sprawl; giving stability to the neighbourhoods, creating a neighbourhood identity; giving the sense of place and providing the blocks with an exclusive and unique character, enhancing the community conditions. However, in the developing countries, there are many issues, which are overloading the shoulder of the designers for such projects such as the arranging of the social services, the fire precaution, the technical solutions for the infrastructure, waste management, vertical circulation, the cost of the running maintenance, which are still a big challenge while thinking about vertical cities. Such a project in the hot-humid country will:

a. Create places that meet social, environmental, cultural, and aesthetic and practical requirements.

b. Improve how people interact with their new vertical city environment.

c. Reduce the negative impacts that human use has upon sensitive urban problems

d. Adding to the general concept, as well as, preparing a primary master plan, then the detailed designs will come next.

e. Residents will have the high value of the sharing spaces to influence the Qualitative Performance of the Voids easy accessibly for time, place, and Activities (figure 15)

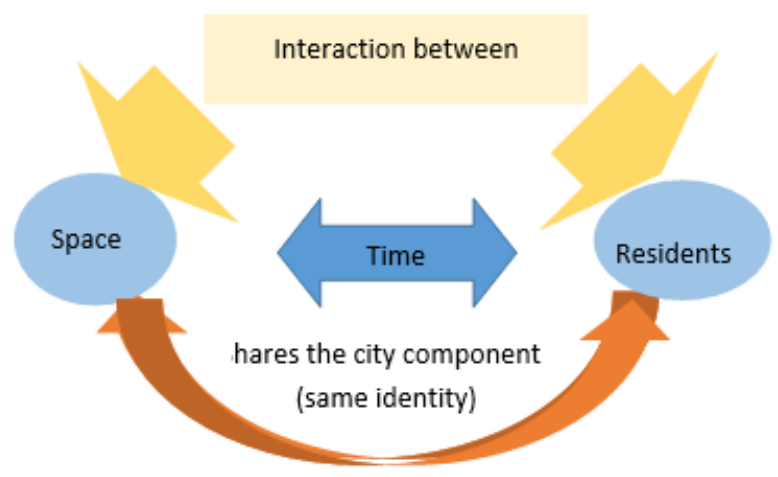

Figure 15. Bound the social interaction within common spaces inside the vertical cities (Authors, 2018).

\section{Acknowledgment}

I would like to state and express my sincere thanks to the father of the first author Mr Bahaa Yusuf for his support and initiative idea for the research. Sincere thanks to Prof. Dr. Agr. Kai Tobias, Department of Spatial Environmental Planning, Technische Universitat Germany and to Ms Susana Saraiva for her sharing knowledge and support.

\section{Conflict of Interests}

The Authors declare no conflict of interest.

\section{REFERENCES}

[1] Ministry of Information Affairs - Kingdom of Bahrain. (2020). Population and Demographics. Mia.gov.bh. Retrieved 1 January 2020, from https://www.mia.gov.bh/ki ngdom-of-bahrain/population-and-demographics/?lang=en.

[2] Kingdom of Bahrain - eGovernment Portal. (2019). Housing. Bahrain.bh. Retrieved 1 January 2020, from https://www.bahrain.bh/wps/portal/!ut/p/a1/lZJLV8IwEIX_ iiy6bDNNSlvcRUAUKYgI0m44bU0fnjYpfYD-e1M4LjyK SHbJ3HvyzZ1BHlojj_u7NPbrVHA_a--eubmbgaljG4-BkC HQmWk9WqsepitdClwpAOz09XtDChwHgNo3T5Pn2z6A jb_7Z8MuleWVMxgNDIC5ccY_Iuf8L8hDXsjrok6Qy2Kx KORZ-9mGcQUSkTMFmopFTXaV8kiU-aGvttJUKY9bbx Gmr8g1cRBZuo5VMGxTNQgxVD9goOIejgjuhYQEwRfri UPhXFYLxo-8ZxL7U9BGchSc5nAlqHWKZP4AaHFh5-N _rEH6tt16VA5D8Jq912h98TTkL3EmgsPauZQHxJYTKln ESIZqTSmfk7ouqmsFFNjv91osRJwxLRS5FiQK_OZKRC VJfohRkS-XuU0-1PEwmk5VL-hmuwntdD4BAfemSg!!/dl 5/d5/L2dBISEvZ0FBIS9nQSEh/.

[3] El-Dardiry, D., \& El-Ghonaimy, I. (2016). COMPARATIVE STUDY FOR DEVELOPING CLOSED VERNACULAR SETTLEMENTS IN EGYPT. IJRDO-Journal of Social Science And Humanities Research, 1(10). ISSN: 2456-2971 
[4] El-Ghonaimy, I., \& Javed, N. (2018). Concomitant of Global Warming and Land Reclamation: Designing a new interface between human kind and sea. Proceedings of the International Conference on Industrial Engineering and Operations Management Pretoria / Johannesburg, South Africa. ISBN: 978-1-5323-5947-7

[5] Cio.gov.bh. (2017). Area of Kingdom of Bahrain by Governorates. Retrieved 7 October 2017, from http://www.cio.gov.bh/cio_ara/English/Publications/Statisti cal\%20Abstract/ABS2013/Ch1/3.pdf_

[6] El-Ghonaimy, I., \& Mohammed, W. (2019). Urban Heat Island in Bahrain: Urban Perspective. Buildings Journal, 9(4). https://doi.org/10.3390/buildings9040096

[7] Nechyba, T., \& Walsh, R. (2004). Urban Sprawl. Journal Of Economic Perspectives, 18(4). https://doi.org/10.1257/0 895330042632681

[8] Wiedmann, F. (2010). Post-Oil Urbanism in the Gulf. http://dx.doi.org/10.18419/opus-77

[9] Data.gov.bh. (2017). Bahrain Open Data Portal, Data Analysis. Retrieved 7 October 2017, from http://www.data.gov.bh/en/DataAnalysis

[10] Pateman, T. (2011). Rural and urban areas: comparing lives using rural/urban classifications.https://doi.org/10.1057/rt.2 011.2

[11] Al Najjar, M. (2018). The Concept of Vertical Cities: The Case of the Kingdom of Bahrain. Lambert Academic Publishing. ISBN: 978-3-659-97959-0

[12] Sure Architecture. (2015). Endless Vertical City. Retrieved 4 January 2020, from http://www.sure-architecture.com/ind ex.php?m=content $\& \mathrm{c}=$ index $\& \mathrm{a}=$ show $\&$ catid $=14 \& \mathrm{id}=21$

[13] JDS Architects. (2006). Shenzhen Logistic City. Jdsa.eu. Retrieved 5 January 2020, from http://jdsa.eu/slc/.

[14] Yoneda, Y. (2010). JDS's Logistic City is a Wind Powered Vertical Forest for Shenzhen. Retrieved 3 January 2020, from

https://inhabitat.com/jdss-logistic-city-is-a-wind-powered-v ertical-forest-for-shenzhen/

[15] OMA Architects. (2013). De Rotterdam. oma.eu. Retrieved 3 January 2020, from https://oma.eu/projects/de-rotterdam.

[16] Hallebrand, E., \& Jakobsson, W. (2016). Structural Design of High-rise Buildings. Faculty Of Engineering LTH, Lund University, Sweden. ISSN: 0281-6679

[17] Rana, N., \& Rana, S. (2014). Structural Forms Systemsfor Tall Building Structures. SSRG International Journal of
Civilengineering (SSRG-IJCE), 1(4). ISSN: $2348-8352$

[18] Shukri, F., \& Misni, M. (2017). THE IMPACT OF ROOF GARDENS AT HIGH-RISE RESIDENTIAL BUILDINGS ON PROPERTY VALUES. WIT Transactions On Ecology And The Environment, 226. https://doi.org/10.2495/SDP170 041

[19] Wark, C., \& Wark, W. (2003). Green Roof Specifications and Standards. The Construction Specifier, 56(8), 2-3. ISBN: 0010-6925

[20] Department of Environment and Climate Change NSW. (2008). Better Practice Guide for Waste Management in Multi-unit Dwellings. Department Of Environment And Climate Change NSW, 65-69. ISBN: 9781741225945

[21] Ecotech Chutes Pvt. Ltd. (2020). Standard Garbage Chute. ecotechchutes. Retrieved 3 January 2020, from http://www.ecotechchutes.com/standard-chute.html.

[22] City of New York Department of Design and Construction. (1999). High Performance Building Guidelines, 65-66. ISBN: 0-07-071159-3

[23] Al-Kodmany, K. (2015). Tall Buildings and Elevators: A Review of Recent Technological Advances. Buildings, 5. https://doi.org/10.3390/buildings5031070

[24] Kinateder, M., Kuligowski, E., \& Omori, H. (2014). The Use of Elevators for Evacuation in Fire Emergencies in International Buildings. National Instituates Of Standards And Technology U.S. Department Of Commerce. https://doi.org/10.6028/NIST.TN.1825

[25] Gupta, L., \& Thawari, S. (2016). Plumbing System in High Rise Building. IJIRST -International Journal For Innovative Research In Science \& Technology, 2(11). ISSN: 2349-6010

[26] United States Environmental Protection Agency. (2020). Drinking Water Distribution Systems. US EPA. Retrieved 3 January 2020, from https://www.epa.gov/dwsixyearreview/ drinking-water-distribution-systems.

[27] Dummies. (2017). Figuring Out Your Drain-Waste-Vent Lines. Dummies. Retrieved 3 January 2020, from https://www.dummies.com/home-garden/plumbing/figuring -out-your-drain-waste-vent-lines/.

[28] Gulf Insider. (2020). Bahrain has a Housing Shortage. Retrieved 1 Jan. 2020, from http://www.gulf-insider.com/ba hrain-housing-shortage/_

[29] King, K., \& Wong, K. (2015). VERTICAL CITY: A SOLUTION FOR SUSTAINABLE LIVING. China Social Sciences Press, 1st Edition, 27. ISBN 13: 9787516151075 